\title{
Ground/Flight Correlation of Aerodynamic Loads with Structural Response
}

\author{
Arun S. Mangalam* \\ Tao of Systems Integration, Inc., Hampton, Virginia, 23666 \\ and \\ Mark C. Davis ${ }^{\dagger}$ \\ NASA Dryden Flight Research Center, Edwards, California, 93523
}

\begin{abstract}
Ground and flight tests provide a basis and methodology for in-flight characterization of the aerodynamic and structural performance through the monitoring of the fluid-structure interaction. The NF-15B flight tests of the Intelligent Flight Control System program provided a unique opportunity to test the correlation of aerodynamic loads with points of flow attaching and detaching from the surface, which are also known as flow bifurcation points, as observed in a previous wind tunnel test performed at the U.S. Air Force Academy (Colorado Springs, Colorado). Moreover, flight tests, along with the subsequent unsteady aerodynamic tests in the NASA Transonic Dynamics Tunnel (TDT), provide a basis using surface flow sensors as means of assessing the aeroelastic performance of flight vehicles. For the flight tests, the NF-15B tail was instrumented with hot-film sensors and strain gages for measuring root-bending strains. This data were gathered via selected sideslip maneuvers performed at level flight and subsonic speeds. The aerodynamic loads generated by the sideslip maneuver resulted in a structural response, which were then compared with the hotfilm sensor signals. The hot-film sensor signals near the stagnation region were found to be highly correlated with the root-bending strains. For the TDT tests, a flexible wing section developed under the U.S. Air Force Research Lab SensorCraft program was instrumented with strain gages, accelerometers, and hot-film sensors at two span stations. The TDT tests confirmed the correlation between flow bifurcation points and the wing structural response to tunnel-generated gusts. Furthermore, as the wings structural modes were excited by the gusts, a gradual phase change between the flow bifurcation point and the structural mode occurred during a resonant condition.
\end{abstract}

\section{Nomenclature}

$\begin{array}{ll}\text { AFRL } & =\text { Air Force Research Laboratory } \\ \text { AOS } & =\text { airstream oscillation system } \\ \text { CFD } & =\text { computational fluid dynamics } \\ \text { CSD } & =\text { computational structural dynamics } \\ \text { CTA } & =\text { constant temperature anemometer } \\ \text { CVA } & =\text { constant voltage anemometer } \\ \text { EMI/RFI } & =\text { electromagnetic interference/radio-frequency interference } \\ \text { FBP } & =\text { flow bifurcation point } \\ \text { FSI } & =\text { fluid structure interaction } \\ \text { gRMS } & =\text { root-mean-square acceleration } \\ \text { IFCS } & =\text { Intelligent Flight Control System } \\ \text { LCO } & =\text { limit cycle oscillation } \\ \text { LESP } & =\text { leading-edge stagnation point } \\ \text { PRS } & =\text { phase-reversal signature }\end{array}$

\footnotetext{
*Staff Scientist, Tao of Systems Integration, Inc., Hampton, Virginia, 23666, AIAA Member.

${ }^{\dagger}$ Aerospace Engineer, Aerodynamics and Propulsion Branch, P.O. Box 273/MS 2228, AIAA Member. 


$\begin{array}{ll}\text { SEP } & =\text { separation point } \\ \text { SNR } & =\text { signal-to-noise ratio } \\ \text { TDT } & =\text { Transonic Dynamics Tunnel } \\ \text { TsAGI } & =\text { Central Aerohydrodynamic Institute } \\ \text { UAV } & =\text { unpiloted autonomous vehicle } \\ C_{L} & =\text { lift coefficient } \\ x & =\text { instantaneous SEP location } \\ \dot{x} & =\text { rate of change for SEP location } \\ x_{0} & =\text { SEP location for a given angle of attack } \\ \alpha & =\text { angle of attack, deg } \\ \dot{\alpha} & =\text { change in angle of attack, deg/sec } \\ \tau & =\text { time constraint }\end{array}$

\section{Introduction}

$\mathrm{T}$ he increasing demand for performance subjects present-day aircraft to progressively more complex fluid structure interaction (FSI) between the unsteady flowfields and the flexible wing structures. ${ }^{1}$ The nonlinear coupling between the aerodynamics and the structural response can lead to adverse aeroelastic conditions such as buffet, limit cycle oscillation (LCO), or flutter., ${ }^{2,3}$ On the favorable side, the FSI may be utilized to aerodynamically twist flexible wings to improve maneuverability of high-speed aircraft. ${ }^{1}$ In both of these cases, the maneuverability and controllability of the aircraft is severely affected by the FSI. Consequently, to improve the aircraft aeroelastic characteristics, both the aerodynamic and structural loads need to be simultaneously monitored and ultimately controlled.

The role of unsteady aerodynamics and its relationship to wing structural response is important for understanding the FSI. Viscous effects (e.g., boundary layer transition from laminar to turbulent flow, flow separation and reattachment, and vortex dynamics) affect the unsteady aerodynamic forces imposed on the wing structure. ${ }^{4}$ For example, at high angles of attack some aircraft exhibit tail buffet from unsteady aerodynamic forces emanating from leading-edge vortices exciting structural modes on aft lifting surfaces such as vertical tails. ${ }^{4,5}$ Although viscous effects are clearly vital to the understanding of vehicle performance, reliable tools that can be used by aircraft engineers for design and/or performance evaluation on a routine basis are difficult to develop because of the complexities involved in assessing fluid flow and its interactions at any speed.

Empirically, the FSI has primarily been characterized from a structural perspective, using computational aeroelasticity codes that combine high fidelity computational fluid dynamics (CFD) ${ }^{6}$ with computational structural dynamics (CSD) to infer the aerodynamic loads from the measured structural response. This inverse approach is apparently only as reliable as the unsteady aerodynamic model being used to infer aerodynamic response from the measured structural response and the associated structural and unsteady aerodynamic models. ${ }^{7}$ Developing reliable computational aeroelasticity codes is clearly an ongoing research effort. ${ }^{8}$

Ideally, the aerodynamic loads and structural response should both be experimentally determined to assess actual vehicle aeroelastic performance and, if possible, provide experimental data to validate the aeroelasticity codes. This process entails instrumenting the wing structure with both high-bandwidth flow sensors to measure the flow state, and strain gages and accelerometers to measure the structural state. ${ }^{9}$ The typical method of measuring aerodynamic loads is by instrumenting the wing with surface pressure sensors to obtain lift through integration. ${ }^{10}$ Unfortunately, there are numerous factors that affect the measurement reliability of flow sensors in a flight environment including altitude, temperature, density, humidity, dust, vibration, and electromagnetic and radio-frequency interference (EMI/RFI).

Essentially, the flow sensors must separate the effect of the changing ambient environment from the aerodynamic loads measurement. Considering this environment, pressure sensors must measure the flow fluctuations from the deflections of an inertial diaphragm that, although usually not directly exposed to the environment, is layered with protective coating or tubing further damping the diaphragm structural response and increasing the latency. ${ }^{11}$ The possibility exists to deconvolve unsteady pressure response, but it will require significant effort to calibrate and model the pressure sensor and pneumatic lags. ${ }^{12}$ Lags happen to be critical for accurate aeroelastic modeling because they impact the nonlinear relationship between the aerodynamic forcing function and the lagged structural response. As a result, to improve flight-testing methodology and productivity, new low-latency approaches should be explored to measure and correlate unsteady aerodynamic forces with structural response. 


\section{Background}

A large number of past flight tests have examined ways to measure aerodynamic loads and their effect on aircraft structures during flight. This interaction is an area of study critical to the development of new aircraft design, and a subject that the aeronautical technical community is seeking to better understand. Figure 1 shows one of the many test vehicles used to obtain this data. In this section, the basic measurement technique and the concepts necessary to relate the unique measurement to relevant aircraft performance parameters are described.

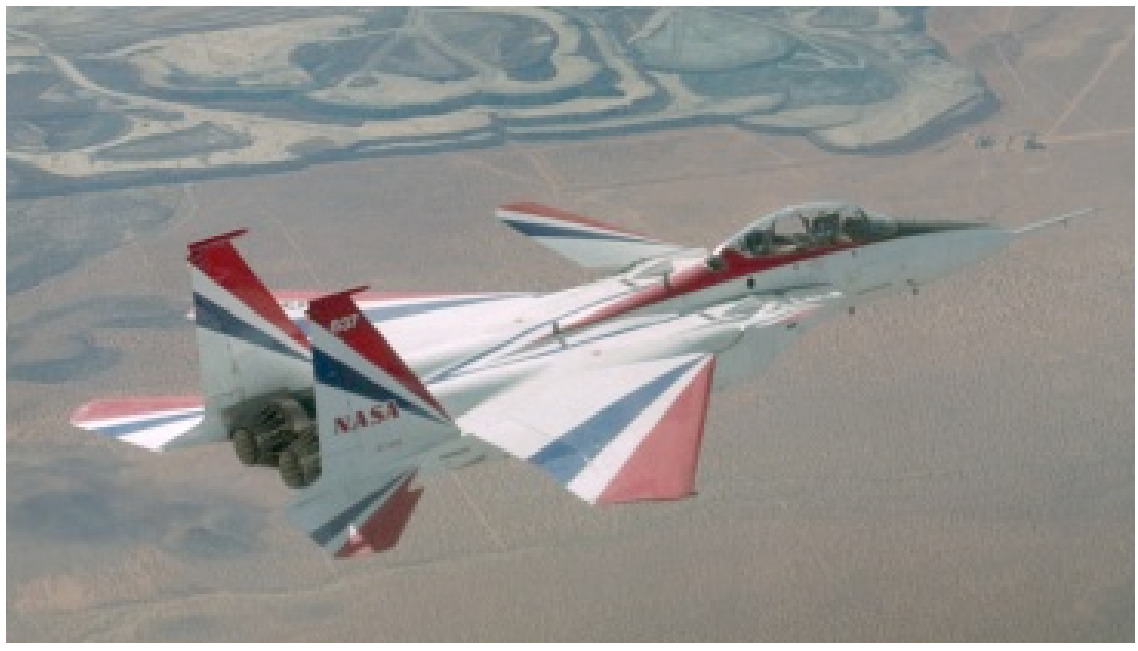

Figure 1. The NF-15B test vehicle.

\section{A. Phenomenological Approach to Unsteady Aerodynamics and Aeroelasticity}

Flow phenomena such as leading-edge stagnation point (LESP) and separation point (SEP) are related to circulation. Streamline bifurcation occurs when the flow attaches to (LESP) or separates from the body (SEP). Flow separation occurs when the flow is unable to negotiate positive pressure gradients. In certain conditions, the separated flow could also reattach itself to the body. Figure 2 depicts an idealized picture of the flow bifurcation points (FBP) for an airfoil section. The circulation around an airfoil can be determined through the Kutta condition requiring that the rear stagnation point be located at the sharp trailing edge. Flow separation results in a significant loss in circulation as the rear stagnation point moves upstream. So as the LESP moves downstream on the pressure side with higher angle of attack $(\alpha)$, the aerodynamic lift increases as long as SEP remains at the trailing edge. As the flow is unable to negotiate the positive pressure gradient at higher angles, the flow separates and the SEP moves upstream causing a loss in lift and an increase in profile drag.

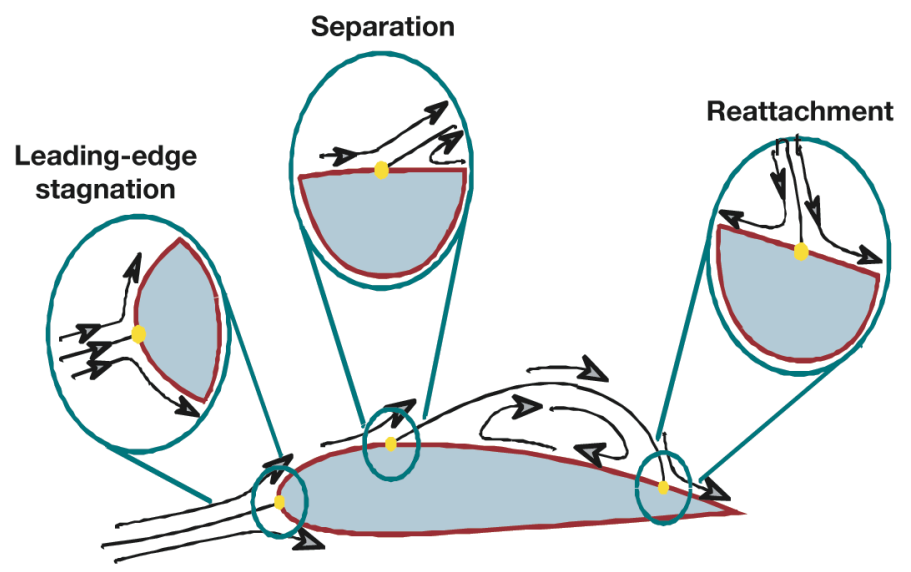

Figure 2. Flow bifurcation points.

American Institute of Aeronautics and Astronautics 
The premise then is that by measuring surface parameters in the boundary layer (i.e., FBPs), the circulation and consequently the aerodynamic forces can be characterized, which would then imply a correlation between the locations of important boundary layer phenomena and aerodynamic forces. This intuition was pursued independently by Goman and Khrabrov, ${ }^{13}$ and Mangalam and Suryanarayan. ${ }^{14}$

Goman and Khrabrov from the Central Aerohydrodynamic Institute (TsAGI) (Moscow, Russia) developed a state-space model incorporating flow phenomena, such as flow separation and vortex breakdown, for delta wings to model and control unsteady aerodynamics for highly maneuverable fighter aircraft. In their model, unsteady aerodynamic loads are determined basically through two expressions, given as Eqs. (1) and (2):

$$
\begin{gathered}
\tau_{1} \dot{x}+x=x_{0}\left(\alpha-\tau_{2} \dot{\alpha}\right) \\
C_{L}(\alpha, x)=(1+\sqrt{x})^{2} \alpha \pi / 2
\end{gathered}
$$

where $\alpha$ is the angle of attack, $x_{0}$ is the SEP location at $\alpha$ under steady-state flow conditions, and $x$ is the instantaneous SEP location as a fraction of chord length. The time constants, $\tau_{1}$ and $\tau_{2}$, have to be determined experimentally through a test matrix of accelerations and rotation rates in a wind tunnel facility. The instantaneous SEP location, $x$, is determined through the solution of the ordinary differential equation. The SEP location and $\alpha$ are then used as input to calculate the lift coefficient, $C_{L}$. To verify, if $x=1$ (i.e., Kutta condition and $C_{L}$ is $2 \pi \alpha$ ), then the value given is the inviscid theory for a symmetric airfoil. This approach of using a single flow phenomena as a state in flight control equations was applied in several wind tunnel experiments ${ }^{15}$ and used as an analytical model for Russian military fighter aircraft. ${ }^{13}$

Unfortunately, the Goman and Khrabrov state-space model requires extensive wind tunnel testing to obtain the time constants necessary to model the unsteady aerodynamics. Such an effort is time-consuming, costly, and limited in its applicability with respect to flexible aircraft. Analytically, the Goman and Khrabrov model is limited in its applicability to rigid structures, because nonuniform flow along flexible structures undergoing aeroelastic deformations presents a complex aeroservoelastic problem. Mangalam and Suryanarayan anticipated these limitations and developed a new state-space system that incorporated flow phenomena, such as LESP and SEP, as measured states. ${ }^{14}$ This approach has the potential to develop the state-space control equations as a forward rather than backward problem, since the aerodynamic forcing function and the structural response can be determined one after the other, instead of the more complex inverse problem, i.e., inferring the aerodynamic forcing function from the measured structural response. Inverse problems are typically ill-posed, i.e., existence, uniqueness, and stability are not satisfied under small changes in measured input. Measured input in this case involves the accuracy of the measured structural response in the context of a nonlinear, or linearized, aeroelasticity model. Clearly, a control solution based on a forward problem formulation would be better suited to robust control design, from a numerical and performance perspective.

As a result, several efforts have been ongoing to systematically develop the tools and concepts necessary to apply the phenomenological approach to a flight vehicle. One of the first efforts was to show that viscous effects, such as LESP and SEP, could be correlated with the aerodynamic loads in a relatively benign laboratory environment. Wind tunnel tests demonstrated that the locations of FBPs could be used to estimate aerodynamic loads. ${ }^{15}$ In this experiment, the LESP locations, SEP locations, and surface pressure measurements were obtained on a National Advisory Committee for Aeronautics (NACA) 0015 airfoil for steady and harmonic pitch oscillations. A simple empirical model for $C_{L}$, as a function of LESP and SEP locations, was derived during steady-state conditions before and after stall and is given as Eqs. (3) and (4), respectively:

$$
\begin{aligned}
& C_{L}=0.2051 x_{\mathrm{LESP}}+0.0002 x_{\mathrm{SEP}} \\
& C_{L}=0.1113 x_{\mathrm{LESP}}+0.0406 x_{\mathrm{SEP}}
\end{aligned}
$$

As indicated in Eqs. (3) and (4), when the instantaneous LESP and SEP locations are known during unsteady maneuvers, unsteady aerodynamic lift can be empirically shown by using the LESP and SEP locations. Figure 3(a) depicts the steady-state pressure-derived lift and fitted steady-state aerodynamic lift based on the LESP and SEP locations. Additionally, Fig. 3(b) depicts the extrapolated unsteady aerodynamic lift coefficients as a function of 
pitch angle. Clearly from this preliminary wind tunnel test, unsteady aerodynamic forces can be uniquely determined by just LESP and SEP, as opposed to just the pitch angle, which corresponds to two different lift coefficients depending on the pitch rate. The next effort after this demonstration was to determine if this phenomenological approach could work in flight.
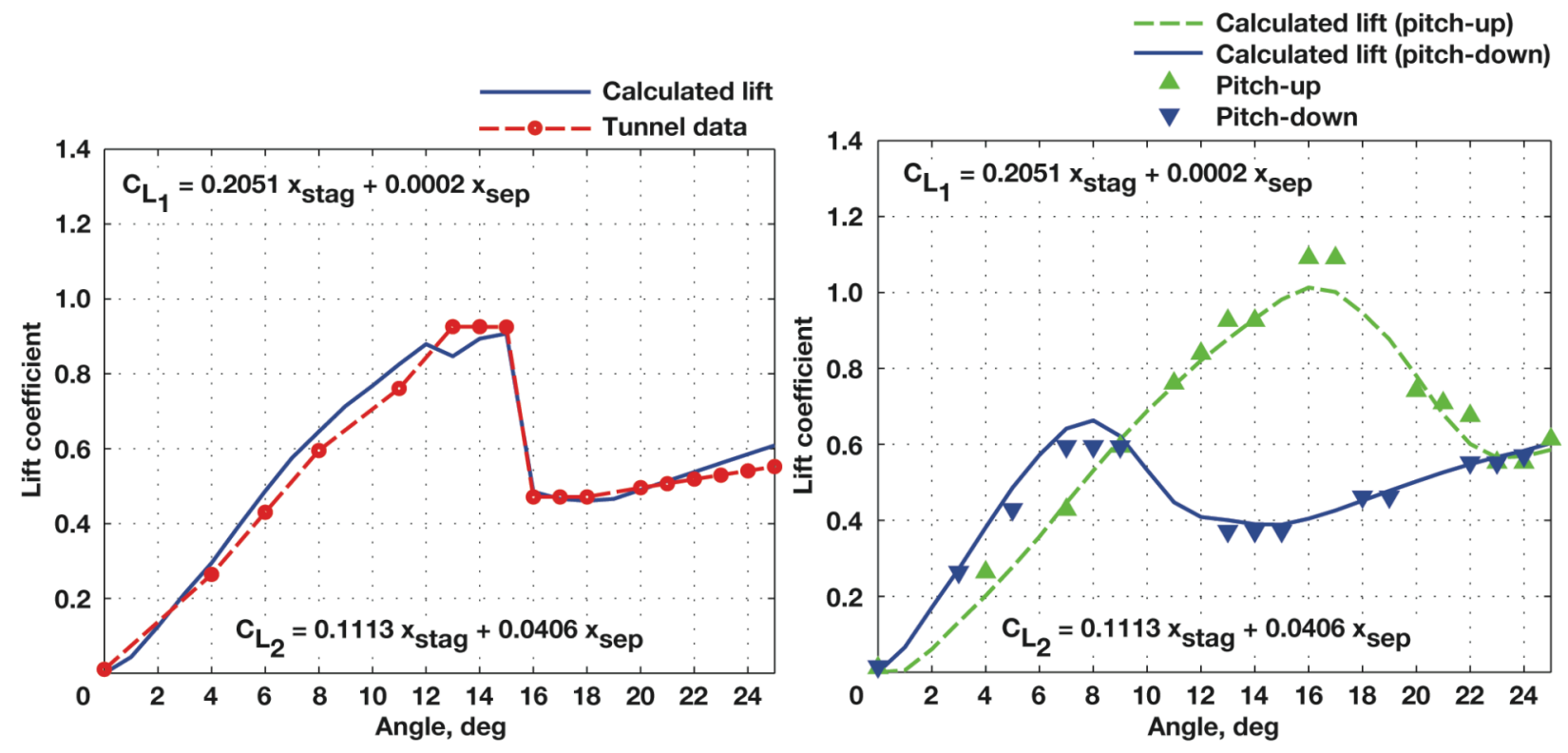

a). Steady-state lift and calculated steady-state lift.

b). Lift with unsteady-state flow oscillation and calculated lift with unsteady flow oscillation.

Figure 3. Extrapolation of unsteady aerodynamic lift.

\section{B. Description of the Test Aircraft}

The test aircraft, National Aeronautics and Space Administration (NASA) NF-15B, tail number 837 (Fig. 1), is a highly modified preproduction, two-seat F-15B (McDonnell Douglas Corporation, St. Louis, Missouri, now the Boeing Company, Chicago, Illinois) aircraft. Modifications include two canards mounted on the upper inlet area forward of the wing. The canards are modified F-18 (McDonnell Douglas Corporation, now The Boeing Company, Chicago, Illinois) horizontal tail surfaces, and their position is scheduled to angle-of-attack changes. The aircraft is powered by two F100-PW-229 Pratt \& Whitney (East Hartford, Connecticut) engines equipped with axisymmetric thrust-vectoring nozzles. The thrust-vectoring capabilities were not used during this series of flights. The aircraft is controlled by a quadruplex digital fly-by-wire flight control system. All mechanical linkages between the control stick, rudder pedals, and control surfaces have been removed from the aircraft. ${ }^{16}$

\section{Measurement System}

Thermal anemometry in conjunction with nonintrusive hot-film sensors can measure viscous effects, such as shear stress, with a relatively high frequency response and minimal sensor lag and processing latency. Hot-film sensing is based on indirectly calculating flow properties by measuring the amount of heat dissipated from a heated sensor to the flow. Unlike pressure sensors that primarily measure the normal forces, hot-film sensors primarily measure the tangential forces (e.g. shear) without any delay-adding moving parts. However, accurately obtaining reliable shear stress measurements over a wide range of frequencies is a notoriously difficult problem, because the frequency and phase characteristics of the hot-film sensor depend on the relatively complex heat transfer condition with the sensor substrate. ${ }^{17,18}$ Since hot-film sensors are directly exposed to the flow environment, they are also even more susceptible to adverse effects from the ambient flow environment than pressure sensors. For example, when embedded on aircraft structures, hot-film sensors are essentially a long metallic antenna picking up stray electromagnetic signals with hardly any way to shield the exposed heated resistor. Yet, another severe problem with the use of thermal anemometry is the change in ambient temperature. This change in temperature not only affects the heat transfer conditions and measurement reliability, but for certain anemometers (i.e., constant temperature 
anemometer (CTA)) the potential for sensor failure is created because a temperature drop (e.g., change in altitude) will induce an increased amount of current to keep the same temperature, which frequently results in overcurrent.

The aforementioned problems with hot-film sensing can be avoided if proper instrumentation and signal processing techniques are used. As a signal-processing example to measure a reliable flow parameter, instead of the absolute value of skin friction, multiple sensor signals can be referenced with respect to each other, and the objective can be limited to quantitatively determining flow phenomena characteristics such as the LESP location. Such flow phenomena include FBPs such as LESP, SEP, and flow reattachment point (Fig. 2). Previous flow measurement studies have shown the capability to extract FBPs on various airfoils, wing surfaces, laminar and turbulent flows, and from subsonic to supersonic speeds using unique signal processing techniques such as the use of phase-reversal signatures (PRS) in the time and/or frequency domain. ${ }^{14,15,19-23}$ All of these techniques depend on a high signal-tonoise ratio (SNR), so even with advanced signal processing techniques, instrumentation plays a vital role.

Regarding instrumentation, the use of the constant voltage anemometer (CVA) to drive the hot-film sensors has been observed to provide high SNR and wide bandwidth in the presence of EMI/RFI and cable capacitance effects even with unshielded sensors and cabling. ${ }^{23}$ Cable capacitance effects play an important role in accurate temperature measurement, since simple vibration of connecting cables will cause long-duration measurement drift due to triboelectric effects. ${ }^{24,25}$ The CVA has been utilized in numerous environments from subsonic to hypersonic ground test facilities to unpiloted autonomous vehicles (UAV) and high-speed aircraft. ${ }^{14,15,19-23}$ As a practical demonstration of the high SNR and high frequency response, Fig. 4 depicts the spectra of the signal obtained from a sensor embedded on a cylinder near the leading edge (Fig. 5). The 3-kHz signal represents the vortex shedding frequency, demonstrating that highly relevant circulatory oscillations and FBP movement can be captured with fast response and without any a priori calibration. Flow phenomena and local flow angularity can be captured at rates far exceeding $3 \mathrm{kHz}$, with minimum latency and minimal calibration requirements, providing a unique opportunity to robustly observe and control relevant surface fluid dynamics with high temporal and spatial resolution.

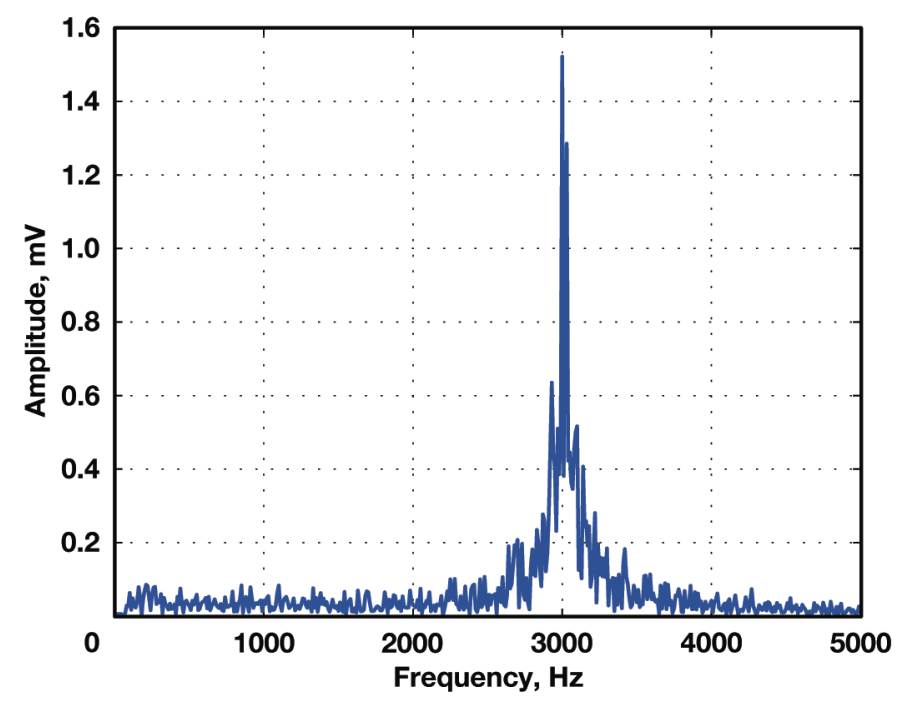

Figure 4. Cylinder vortex shedding frequency. 


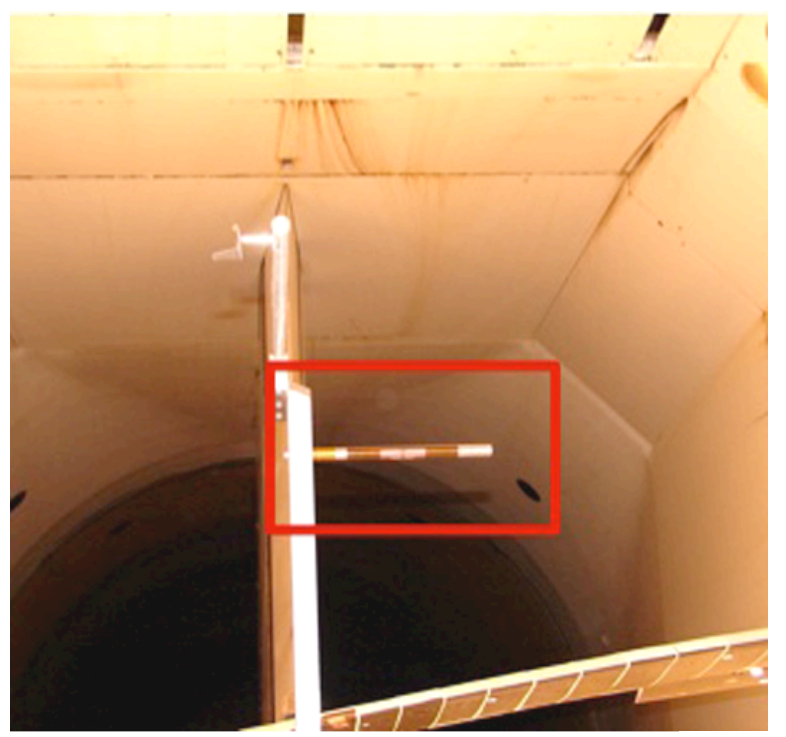

a). Cylinder used in Transonic Dynamic Tunnel testing.

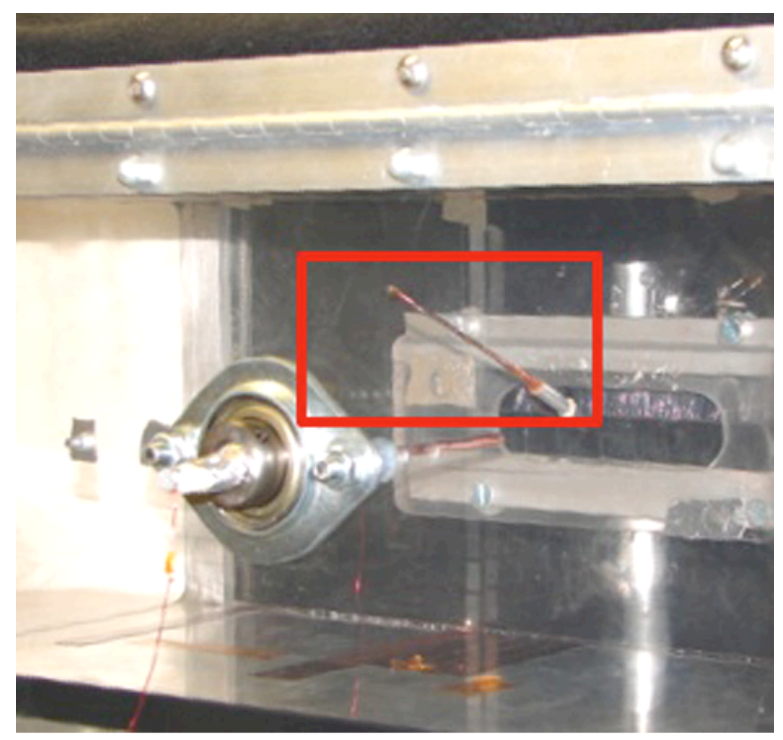

b). Cylinder used to conduct frequency test.

Figure 5. Cylinders used by Tao Systems to conduct frequency and tunnel testing.

\section{Test Setup and Results}

As extensions of the previous efforts, two tests were conducted: NASA NF-15B flight test and an Air Force Research Laboratory (AFRL) SensorCraft ground test. This section will first discuss the NF-15B flight test and results, and then discuss the aeroelasticity test involving the AFRL SensorCraft model.

\section{A. NF-15B Flight Test: Aerodynamic Loads on the Tail}

The NASA NF-15B flight vehicle provided a unique testbed to assess whether the phenomenological approach is feasible in a realistic flight environment. Under the Intelligent Flight Control System (IFCS) flight research project, NASA was using the NF-15B flight test platform to develop and demonstrate a novel self-learning control system that could efficiently and safely recover from a control surface failure. ${ }^{26}$ An opportunity existed to apply flow sensors onto the lifting surfaces to obtain additional aerodynamic data (Fig. 6). The objective was to demonstrate the correlation between the flow phenomena (i.e., FBPs) and structural loads during pseudo-steady maneuvering.

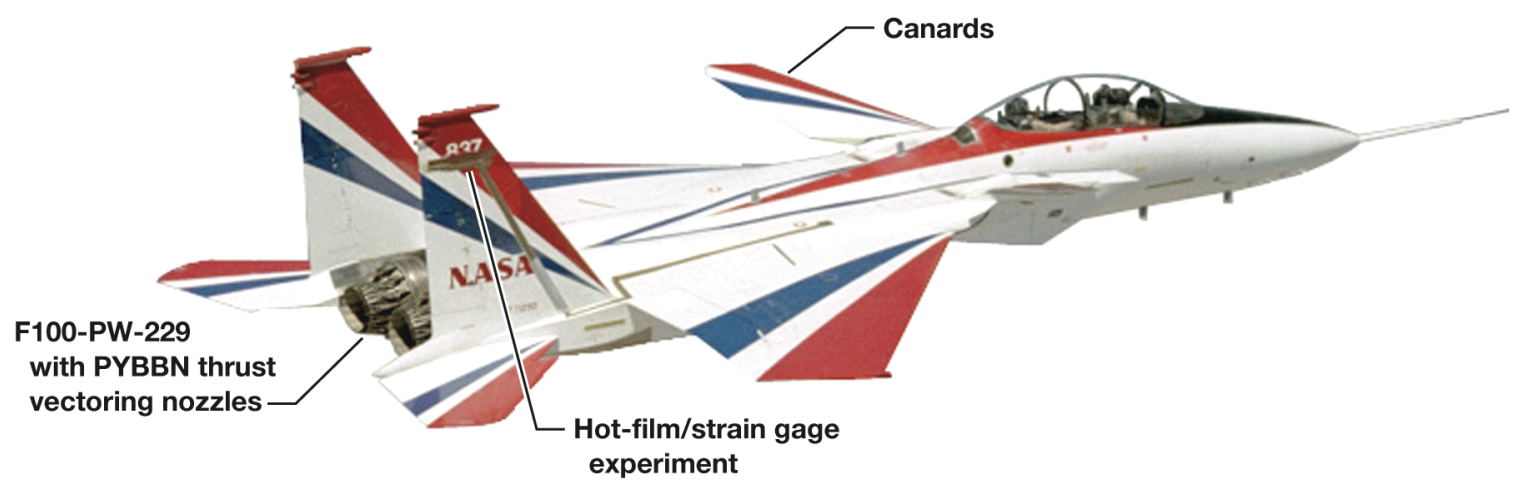

Figure 6. NASA NF-15B flight testbed.

To validate the high correlation between the FBPs and the aerodynamic loads, the NF-15B right tail was instrumented with hot-film sensors at the leading edge. Figure 7 indicates the location of sensors high on the tail. The NF-15B was already instrumented with strain gages at numerous locations, most importantly the tail root. The flight environment provides a uniquely difficult environment for accurate measurement. In this case, the instrumentation task was substantially more difficult considering that the hot-film sensors had to be wired internally 
and externally, and also had to be unshielded so as to not disturb the flow with cable thickness (Figs. 7(a) and (b)). A multichannel automated CVA was fabricated for driving the hot-film sensors with only a single-ended interface and ruggedized for a temperature range of -40 to $+160^{\circ} \mathrm{F}$, altitude range of 0 to $50,000 \mathrm{ft}$, and vibration levels of 12.2 gRMS (Curve B in Ref. 27). The installed instrumentation in the ammunition pallet is shown in Fig. 7(c).

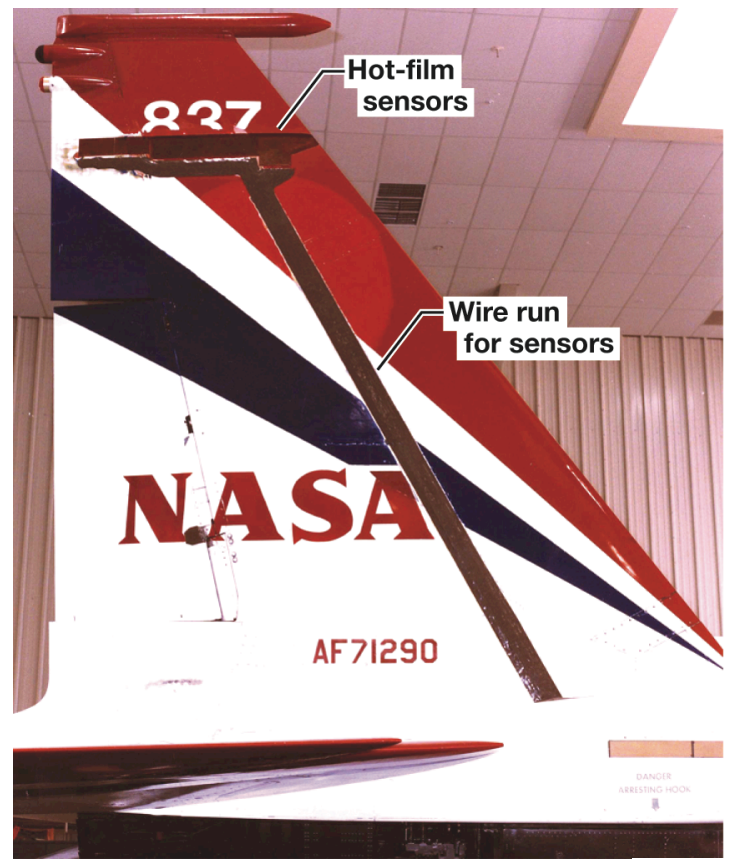

a). Tail number 837 with hot films installed.

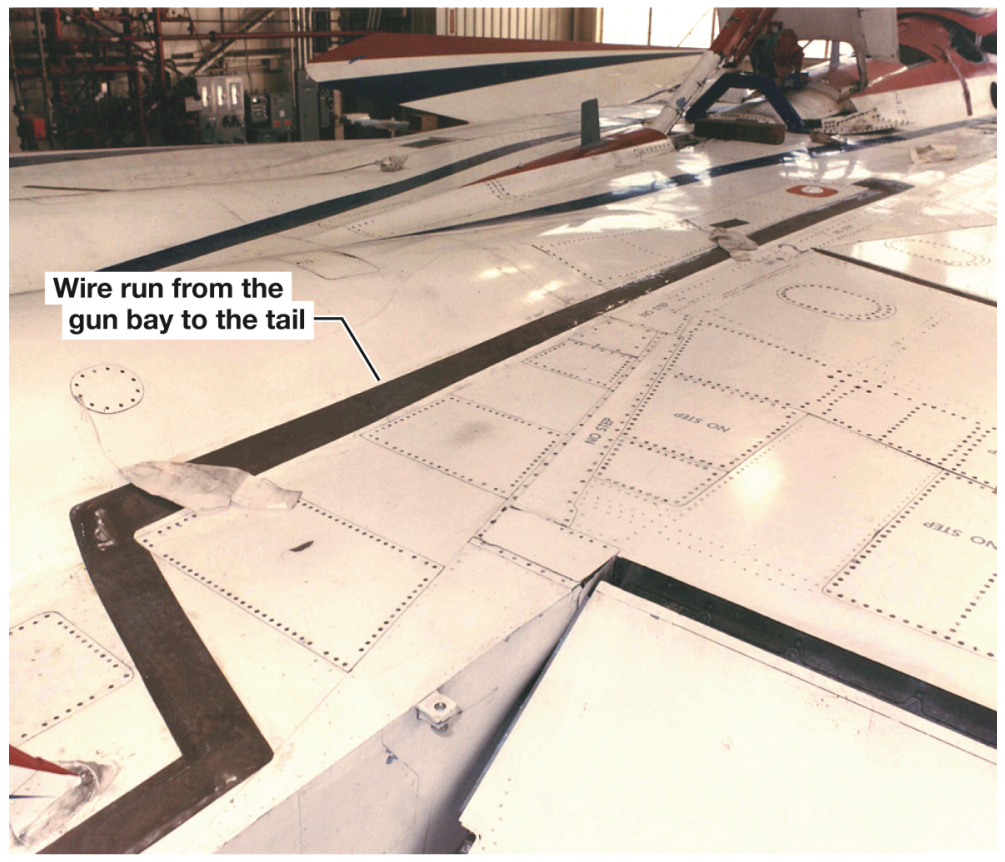

b). Tail number 837 fuselage with hot-film wire run between sensors and CVA box located in gun bay.

Figure 7. NF-15B tail hot-film sensor installation: a) tail view, b) top surface view, and c) CVA.

American Institute of Aeronautics and Astronautics 


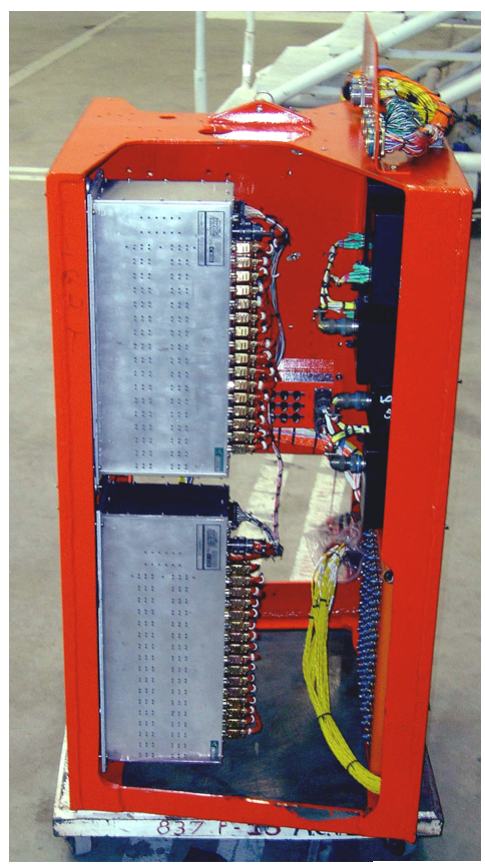

c). Aircraft rack with CVA installed.

Figure 7. Concluded.

The hot-film sensor signals and the strain gage signals were recorded simultaneously at a sampling rate of $400 \mathrm{~Hz}$. The hot-film sensors were filtered with an $80-\mathrm{Hz}$ six-pole low-pass filter, and the strain gage signals were filtered at a few hertz. Several sideslip maneuvers, limited to $\pm 5.0^{\circ}$, were planned to systematically increase the aerodynamic loads on the tail.

Resulting signals from a few of the sideslip maneuvers are shown in Fig. 8. The bottom signal is the strain gage output, the middle signal is the hot-film raw voltage associated with a leading-edge sensor, and the top signal is the sideslip angle that the aircraft flew during the maneuver. As expected, the raw hot-film sensor signals near the stagnation point were highly correlated to the strain gages at the tail root for the sideslip maneuvers. So as the sideslip increased, the aerodynamic side-force increased, and subsequently the root-bending strains increased.

Figure 8 shows the relatively large, clean hot-film signal variation, nearly 100 to $200 \mathrm{mV}$, for a $5^{\circ}$ change in sideslip angle for the hot-film sensor. The hot-film sensor signals did not exhibit any noise deterioration from the aircraft EMI/RFI, providing support for the inclusion of these sensors in a high radio-frequency environment. Furthermore, the use of unshielded wiring does not appear to have deleterious effects. In fact, taking the time derivative of these relatively high SNR raw signals provides an acceleration estimate similar to the rate gyro, as shown in Fig. 9. This flight test demonstrated the potential use of the phenomenological approach through the detection of FBPs in a flight environment. 

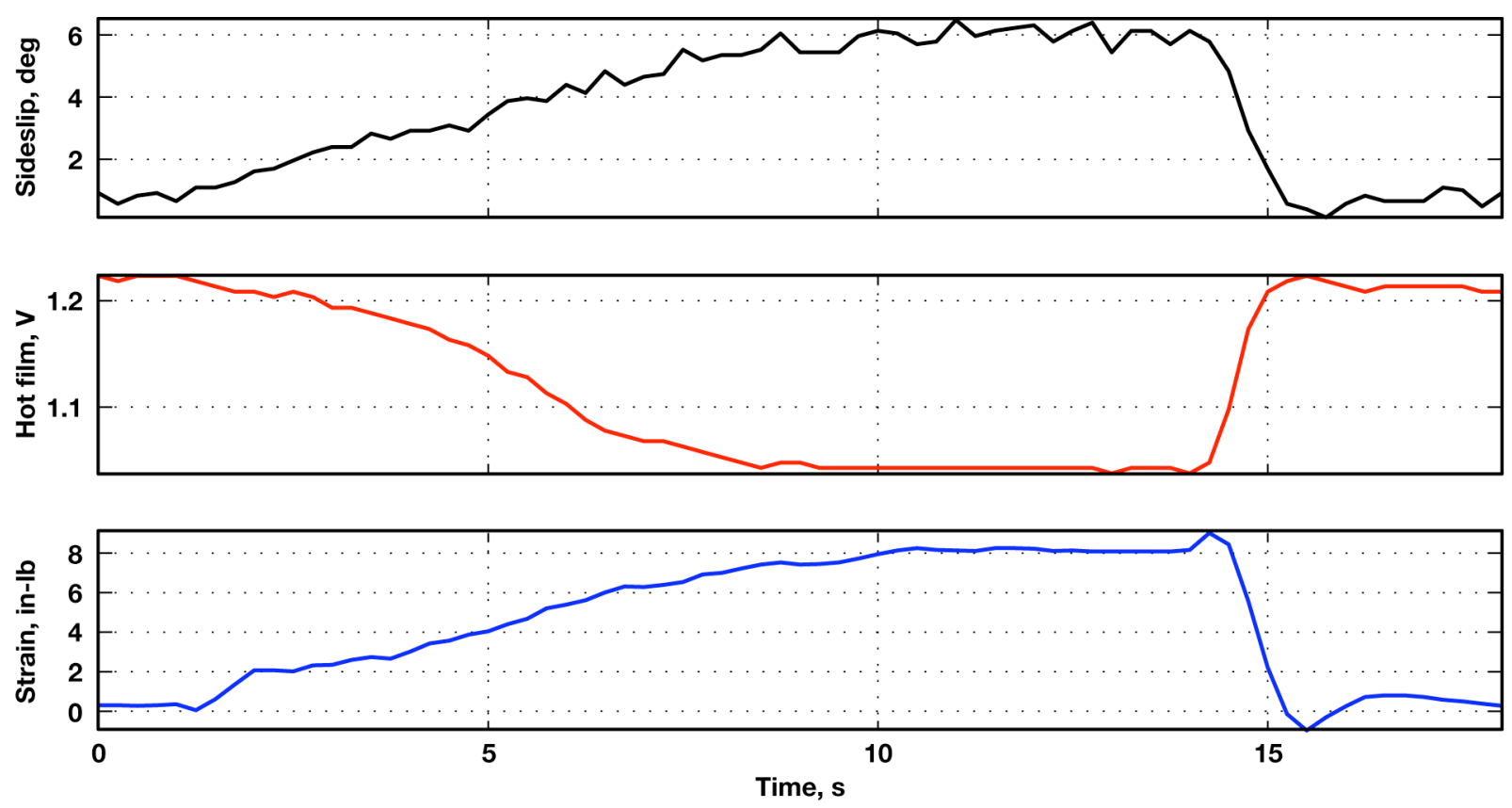

Figure 8. NF-15B hot-film/strain correlation for sideslip maneuver.

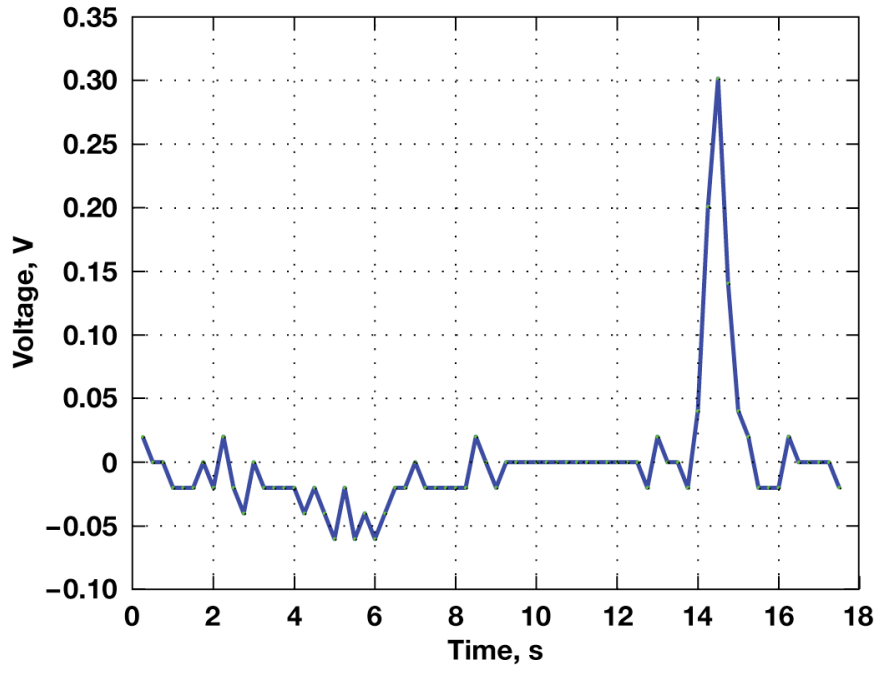

a). Hot-film response.

Figure 9. Yaw rate determined by: a) hot-film sensors and b) rate gyro. 


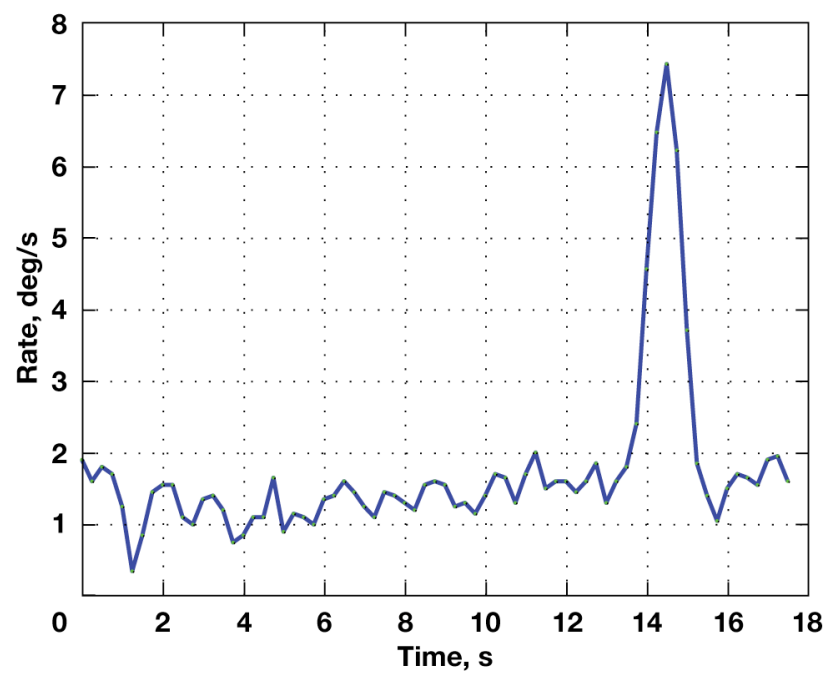

b). Rate gyro yaw rate response.

Figure 9. Concluded.

\section{B. Transonic Dynamics Tunnel Test: Aeroelasticity}

The next step was to demonstrate the difference between aerodynamic and structural load sensing. One method of showing the difference is by instrumenting a flexible wing and measuring the response of the sensors with respect to an aerodynamic disturbance. The AFRL SensorCraft program testbed provided an opportunity to test the phenomenological approach on such a flexible model installed in the NASA Transonic Dynamics Tunnel (TDT). The objective of this test was to develop the relationships between the FBP signals, the aerodynamic forcing function, and the structural response.

The highly flexible SensorCraft wing model was instrumented with hot-film sensors at a few wing sections and numerous other sensors to measure the structural response (Fig. 10). Since the test section and the control room are far apart, the multichannel CVA was wired with up to $150 \mathrm{ft}$ of unshielded wire from the sensors in the test section to the instrumentation in the control room. The TDT tunnel has specialized capabilities, e.g., airstream oscillation system (AOS), to investigate aeroelastic phenomena such as gust loads and flutter. Using the AOS, tunnel-generated gusts were imposed on the flexible wing model at various frequencies.

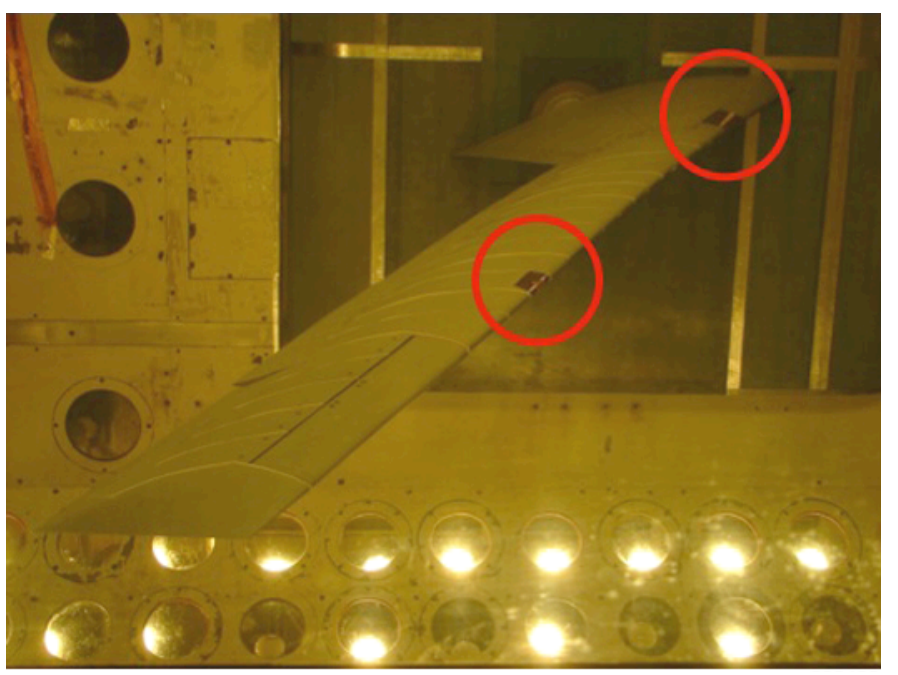

a). AFRL SensorCraft wing model in TDT with sensors indicated.

Figure 10. AFRL SensorCraft wing model. 


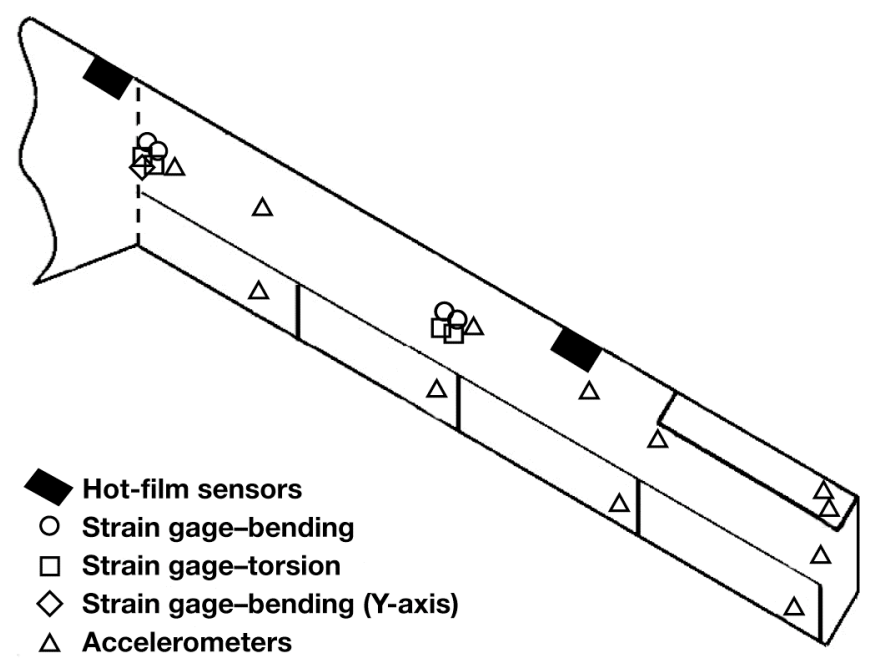

b). AFRL SensorCraft sensor locations.

Figure 10. Concluded.

The sine-swept gusts generated a resonant condition in which the aerodynamic loads coupled with the wing structural modes. Figures 11 and 12 show signals associated with the gust sweeps from near zero to around $10 \mathrm{~Hz}$. As shown from top to bottom in Fig. 11, the signals are the gust vane, inboard LESP, outboard LESP, root-bending moment, and accelerometer in the outboard section. As the gust frequency increases, a structural response delay from the LESP is observed and calculated to be around $40 \mathrm{~ms}$. Two important observations are made: (1) this delay is not constant and changes with gust frequency, and (2) a 40-ms delay is significant time gained using a FBP-based sensor over any structural sensor, including accelerometers, for an aerodynamic disturbance.

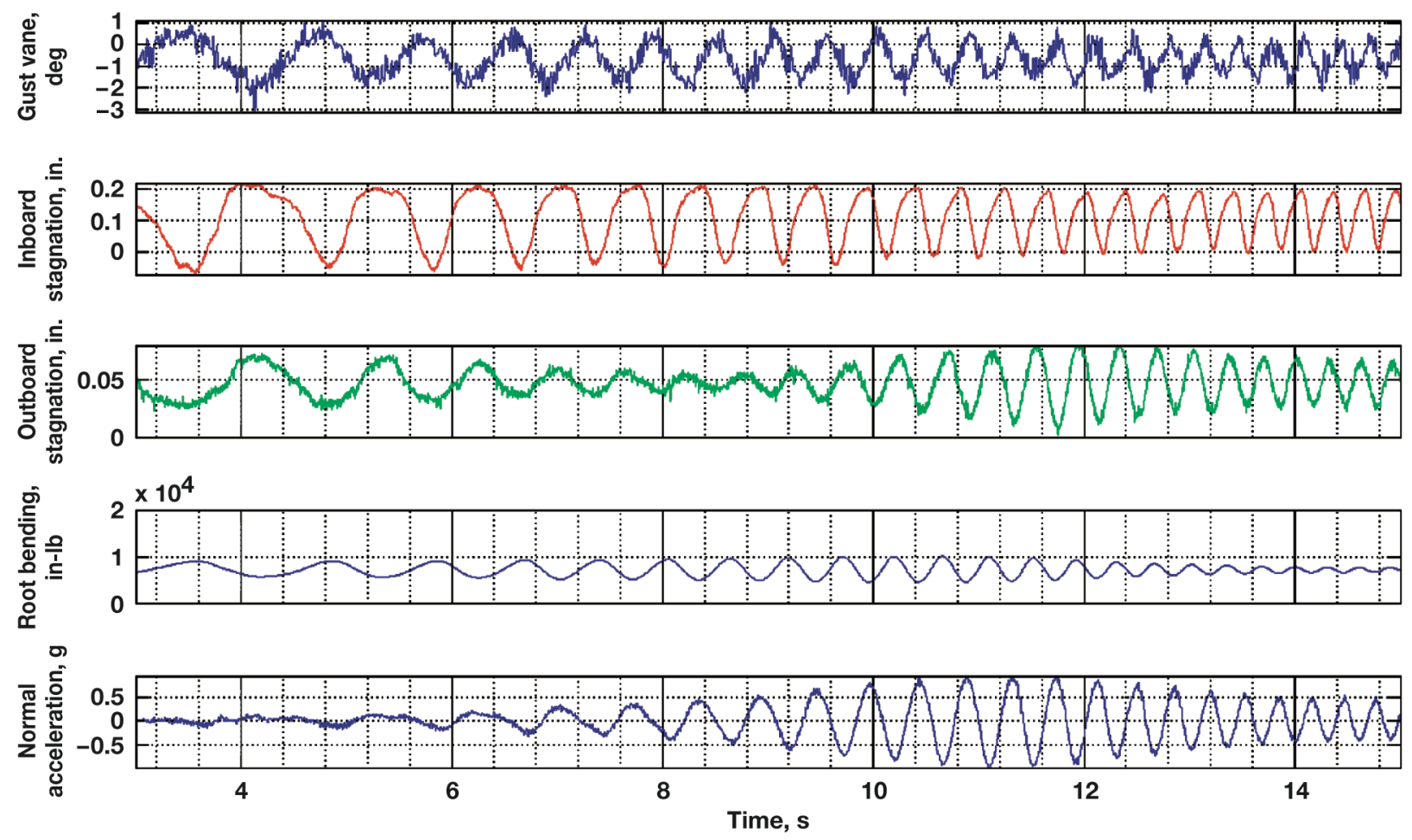

Figure 11. AFRL SensorCraft TDT test: gust sweep 0 to $10 \mathrm{~Hz}$ (structural response).

American Institute of Aeronautics and Astronautics 092407 
Figure 12 provides better detail of a similar gust frequency sweep. This figure includes the raw hot-film sensor voltage to show the difference between the FBP-based sensor and root-bending strain. The top two signals are from hot-film sensors embedded on a cylinder mounted near the gust vane; the third signal is the gust vane; the next pair of signals are from the hot-film sensors embedded near the leading-edge of the inboard section; the next pair of signals are from the hot-film sensors embedded near the leading-edge of the outboard section; and the last signal is the root-bending moment. Each pair of hot-film sensor signals is out-of-phase because the sensors are on either side of the stagnation point, resulting in a phase reversal. These signals were used to determine the LESP at various sections and on the cylinder. The cylinder was used for determining the resulting gust flow angularity and speed from the Strouhal frequency, which is why the cylinder signals appear to have a high spectral content.

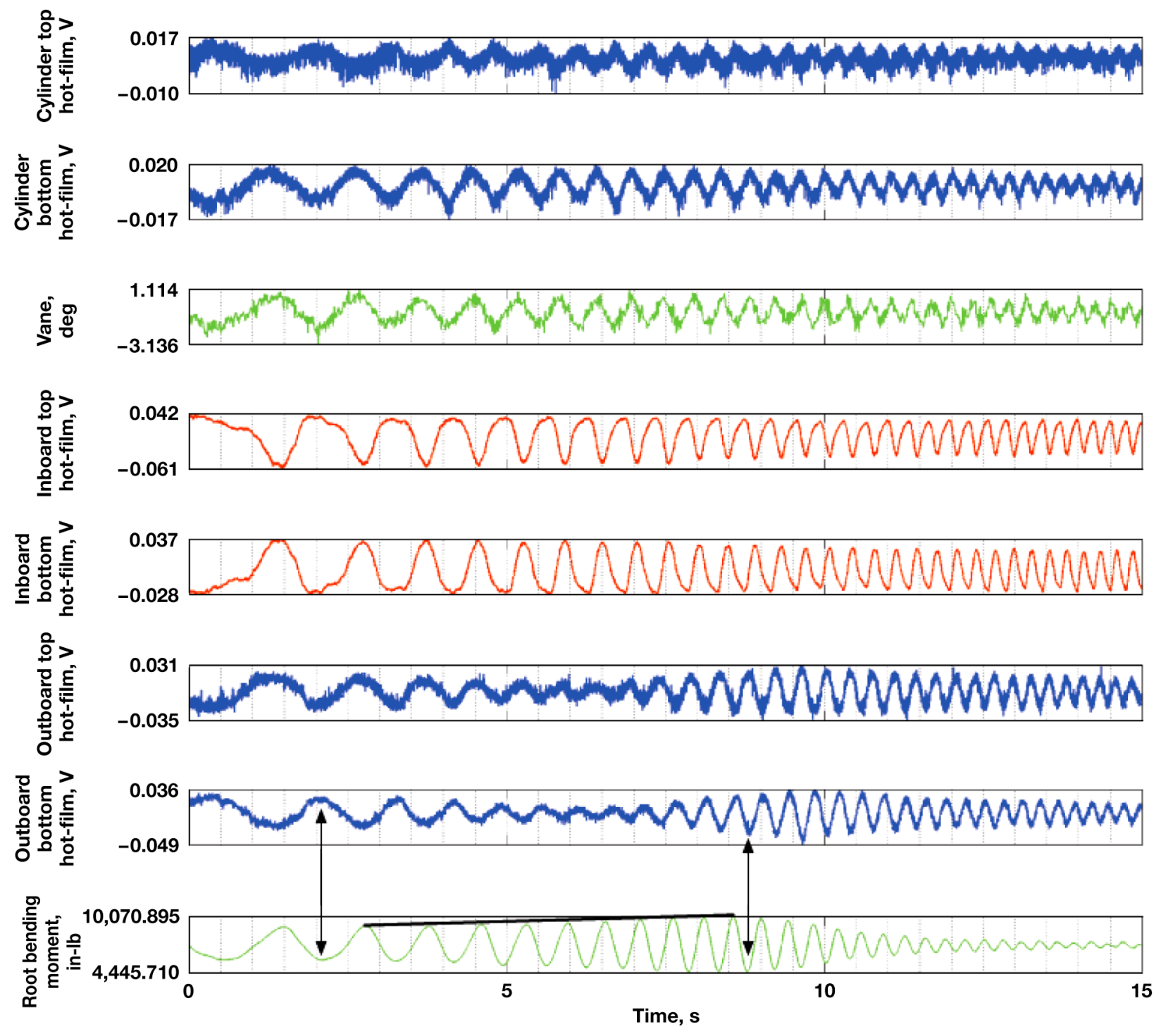

Figure 12. AFRL SensorCraft TDT test: gust sweep 0 to $10 \mathrm{~Hz}$ (hot film).

As shown in Fig. 12, as the gust frequency increases from 0 to $8 \mathrm{~s}$, the root bending continues to increase. However, notice from the gust vane and the cylinder signals that the gust amplitude is decreasing. One way for the structural response to increase while the aerodynamic forcing function is decreasing is if the structure is accumulating energy from the fluid. Due to the bending modes of the wing, resonance occurs as the gust frequency passes through the modal frequency. Interestingly, if the hot-film sensor and root-bending signals are simultaneously observed, the phase angle changes from $180^{\circ}$ to $360^{\circ}$ during the resonance. This phase information could be utilized 
in real time to provide a better quantifiable estimate of the fluid-structure interaction, especially as it relates to the damping for each span location.

Figure 13 depicts the time-frequency analyses of the accelerometer, strain gage, and inboard hot-film signals for the same gust sweep. The inboard hot-film signals have a strong, linear correlation with the gust frequency throughout. This correlation is expected since the hot-film sensors are essentially measuring the aerodynamic disturbance. Conversely, the accelerometer and strain gage signals show dispersion for various times and frequencies. The structural sensors are nonlinearly related to the aerodynamic forcing function. So with a phenomenological approach, the problems associated with aerodynamic disturbance can be linearized. The aerodynamics to structure relationship still remains nonlinear, but it is a much more tractable forward problem.

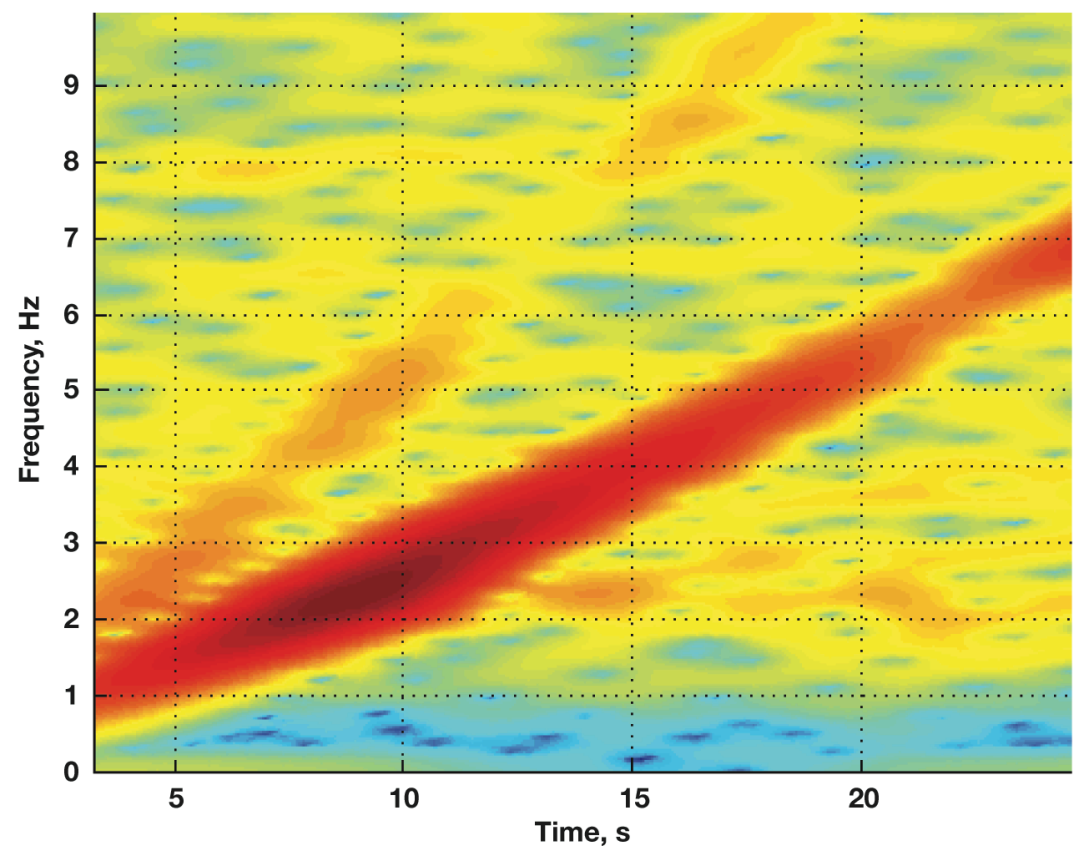

a). Accelerometer time-frequency.

Figure 13. AFRL SensorCraft TDT test: gust sweep 0 to $10 \mathrm{~Hz}$ (change in phase). 


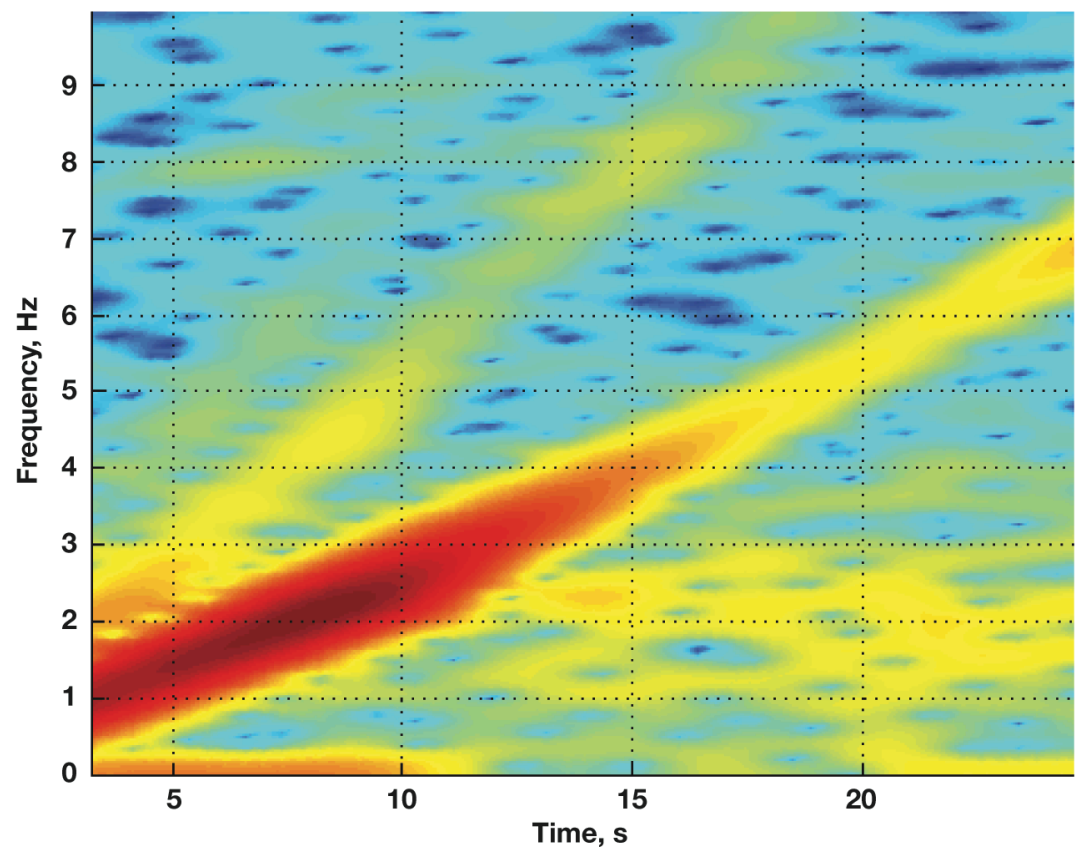

b). Strain-gage time frequency.

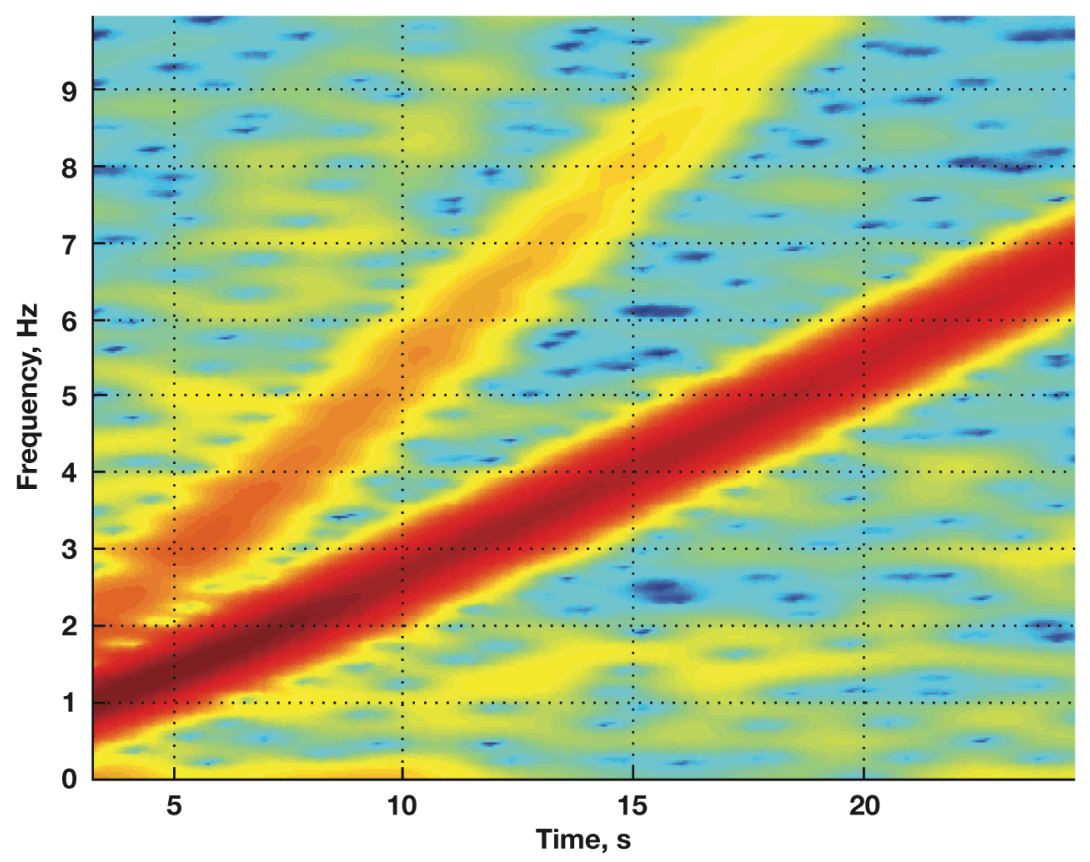

c). Hot-film time frequency.

Figure 13. Concluded.

\section{Conclusion}

The NF-15B flight tests and the unsteady aerodynamic tests in the NASA Transonic Dynamics Tunnel (TDT) provide a basis for including surface flow sensors to assess the aeroelastic performance of flight vehicles. The hotfilm sensor signals near the stagnation region were found to be correlated with the root-bending strains. The TDT tests confirmed the correlation between flow bifurcation points and the wing structural response to tunnel-generated gusts. Furthermore, as the wings structural modes were excited by the gusts, the gradual phase change between the 
flow bifurcation point and the structural modes was tracked during a resonant condition. These tests provide a basis and methodology for the in-flight characterization of the aerodynamic and structural performance through the inflight monitoring of the fluid-structure interaction.

\section{References}

${ }^{1}$ Pendleton, E. W., Bessette, D., Field, P. B., Miller, G. D., and Griffin, K. E., "Active Aeroelastic Wing Flight Research Program: Technical Program and Model Analytical Development," Journal of Aircraft, Vol. 37, No. 4, July-Aug. 2000 , AIAA.

${ }^{2}$ Theodorsen, T., "General Theory of Aerodynamic Instability and the Mechanism of Flutter," NACA Report No. $496,1935$.

${ }^{3}$ Theodorsen, T., and Garrick, I. E., "Mechanism of Flutter: A Theoretical and Experimental Investigation of the Flutter Problem," NACA Report No. 685, 1940.

${ }^{4}$ Mabey, D., "Some Aspects of Aircraft Dynamic Loads Due to Flow Separation," AGARD-R-750, AGARD, 1987.

${ }^{5}$ Pettit, C. L., Brown, D. L., and Pendleton, E., "Wind Tunnel Tests of Full-Scale F/A-18 Twin Tail Buffet: A Summary of Pressure and Response Measurements," AIAA-1994-3476, AIAA, 1994.

${ }^{6}$ Rizzi, A., and Vos, J., "Towards Establishing Credibility in CFD Simulations," AIAA-1996-2029, AIAA, 1996.

${ }^{7}$ Pettit, C. L., "Uncertainty Quantification in Aeroelasticity: Recent Results and Research Challenges," Journal of Aircraft, Vol. 41, No. 5, Sept.-Oct. 2004, AIAA.

${ }^{8}$ Friedmann, P. P., "Renaissance of Aeroelasticity and Its Future," Journal of Aircraft, Vol. 36, No. 1, Jan.-Feb. 1999, AIAA.

${ }^{9}$ Ricketts, R. H., "Experimental Aeroelasticity History, Status and Future in Brief," NASA TM-102651, 1990.

${ }^{10}$ Davis, M. C., and Saltzman, J. A., "In-Flight Wing Pressure Distributions for the NASA F/A-18A High Alpha Research Vehicle," NASA/TP-2000-209018, 2000.

${ }^{11}$ Ainsworth, R. W., Miller, R. J., Moss, R. W., and Thorpe, S. J., "Unsteady pressure measurement," Measurement Science and Technology, Vol. 11, No. 7, pp. 1055-1076, IOP Publishing, 2000.

${ }^{12}$ Whitmore, S. A., and Moes, T. R., "The Effects of Pressure Sensor Acoustics on Airdata Derived From a High-Angle-ofAttack Flush Airdata Sensing (HI-FADS) System," NASA TM-101736, 1991.

${ }^{13}$ Goman, M., and Khrabrov, A., "State-Space Representation of Aerodynamic Characteristics of an Aircraft at High Angles of Attack," Journal of Aircraft, Vol. 31, No. 5, Sept.-Oct. 1994, AIAA.

${ }^{14}$ Mangalam S. M., and Suryanarayan, S., "Critical Aerodynamic Flow Feature Indicators (CAFFI) as Higher Level Control Inputs for Future Aircraft," Proceedings of 19th Congress of the International Council of the Aeronautical Sciences (ICAS 94), AIAA, 1994.

${ }^{15}$ Mangalam, A. S., and Moes, T. R., "Real-Time Unsteady Loads Measurements Using Hot-Film Sensors," AIAA-20045371, AIAA, 2004.

${ }^{16}$ Smolka, J. W., Walker, L. A., Johnson, Major G. H., Schkolnik G. S., Berger, C. W., Conners, T. R., Orme, J. S., Shy, K. S., and Wood, C. B., "F-15 ACTIVE Flight Research Program," 1996 Report to the Aerospace Profession Fortieth Symposium Proceedings, pp. 112-145, SETP, Sept. 1996.

${ }^{17}$ Comte-Bellot, G., "The Physical Background for Hot-Film Anemometry," Turbulence in Liquids, Proceedings of the Fourth Biennial Symposium, Science Press, 1977.

${ }^{18}$ Freymuth, P., "Sine-wave testing of non-cylindrical hot-film anemometers according to the Bellhouse-Schultz model," Journal of Physics E: Scientific Instruments, Vol. 13, No. 1, pp. 98-102, IOP Publishing, 1980.

${ }^{19}$ Mangalam, S. M., Stack, J. P., and Sewall, W. G., "Simultaneous Detection of Separation and Transition in Surface Shear Layers," Fluid Dynamics of Three-Dimensional Turbulent Shear Flows and Transition, AGARD-CP-438, Paper 12, AGARD, 1988.

${ }^{20}$ Mangalam, S. M., Wusk, M. S., and Kuppa, S., "In-Flight Detection of Stagnation, Transition and Separation Using MicroThin Surface Hot-Films," 22nd Annual Symposium Proceedings, Advancement of Flight Test Engineering, Paper 1.2, SFTE, August 1991

${ }^{21}$ Moes, T. R., Sarma, G. R., and Mangalam, S. M., "Flight Demonstration of a Shock Location Sensor Using Constant Voltage Hot-Film Anemometry," NASA TM 4806, 1997.

${ }^{22}$ Mangalam, S. M., "Phenomena-Based Real-time Aerodynamic Measurement System (PRAMS), 2003 IEEE Aerospace Conference Proceedings, Vol. 7, pp. 3347-3356, IEEE, March 2003.

${ }^{23}$ Mangalam, S. M., Flick, P. M., and Brenner, M. J., "Higher Level Aerodynamic Input for Aeroservoelastic Control of Flexible Aircraft," AIAA-2007-6380, AIAA, 2007.

${ }^{24}$ Cross, J. A., Electrostatics: Principles, Problems and Applications, IOP Publishing, 1987.

${ }^{25}$ McConnell, K. G., Vibration Testing: Theory and Practice, Wiley-Interscience, 1995.

${ }^{26}$ Bosworth, J. T., and Williams-Hayes, P. S., "Flight Test Results from the NF-15B Intelligent Flight Control System (IFCS) Project with Adaptation to a Simulated Stabilator Failure," AIAA-2007-2818, AIAA, May 2007.

${ }^{27}$ Corda, S., Franz, R. J., Blanton, J. N., Vachon, M. J., and DeBoer, J. B., "In-Flight Vibration Environment of the NASA F-15B Flight Test Fixture," NASA/TM-2002-210719, 2002. 